\title{
SABERES CULTURAIS AMAZÔNICOS E A CULTURA COMO PRÁXIS: UMA ANÁLISE SOB A TEORIA DO USO DE ZYGMUNT BAUMAN
}

\author{
AMAZON CULTURAL KNOWLEDGE AND CULTURE AS PRAXIS: AN ANALYSIS \\ UNDER THE THEORY OF THE USE OF ZYGMUNT BAUMAN
}

\begin{abstract}
Antonia Fladiana Nascimento dos Santos Especialista em Coordenação Pedagógica. Professora Auxiliar da Universidade do Estado do Amapá - UEAP. Mestranda do Programa de Pós-graduação da Universidade Federal do Amapá/ UNIFAP. Macapá-AP-Brasil. antonia.santos@ueap.edu.br Ângela do Céu Ubaiara Brito
Aoutora em Educação. Professora Adjunta da Universidade do Estado do Amapá. Professora do Programa de Pós-
graduação em Educação da Universidade Federal do Amapá/UNIFAP.
Macapá - AP - Brasil.
angela.brito@ueap.edu.br

Resumo: O presente estudo trata de uma pesquisa qualitativa educacional realizada na rica diversidade cultural da região do Beira Amazonas, no estado do Amapá e investiga quais as contribuições da teoria do uso, fundamentada em Zygmunt Bauman, para a análise cultural da Amazônia amapaense? Tem como objetivo geral analisar a teoria do uso, com base nos princípios do autor Zygmunt Bauman, no contexto cultural da Amazônia amapaense no sentido de compreender os saberes da região. Especificamente, o estudo visa a descrever a história do conceito de cultura, a diferenciar a teoria do uso de outras teorias de análise cultural e a identificar os saberes culturais amazônicos a partir das categorias da teoria do uso de Zygmunt Bauman. A metodologia ancora-se na abordagem qualitativa, pautada no estudo de caso, com a entrevista semiestruturada como técnica de coleta de dados. Os dados foram analisados por meio da análise de conteúdo. Constatou-se que a teoria do uso possui grandes contribuições na análise do universo cultural amazônico tendo em vista a singularidade peculiar do mesmo, assim como colabora na compreensão da riqueza cultural deste universo amazônico em tempos de hibridizações culturais globalizantes na época da
\end{abstract} modernidade líquida.

Palavras-chaves: Teoria do uso. Saberes culturais. Amazônia.

Abstract: The present study deals with a qualitative educational research carried out in the rich cultural diversity of the Beira Amazonas region, in the state of Amapá, which investigates: What are the contributions of the theory of use, based on Zygmunt Bauman, to the cultural analysis of the Amapaense Amazon? Its general objective: to analyze the theory of use, based on the principles of the author Zygmunt Bauman, in the cultural context of the Amapaense Amazon in the sense of understanding the knowledge of the region. Specifically, it is necessary to describe the history of the concept of culture, differentiate the theory of use from other theories of cultural analysis and identify the Amazonian cultural knowledge from the categories of the theory of use of Zygmunt Bauman. The methodology is based on the qualitative approach, based on the case study, with the semi-structured interview as a data collection technique. The data were analyzed through content analysis. It was found that the theory of use has great contributions in the analysis of the Amazonian cultural universe in view of its peculiar singularity, as well as collaborating in the understanding of the cultural richness of this Amazonian universe in times of globalizing cultural hybridizations in the age of liquid modernity.

Keywords: Use theory. Cultural knowledge. Amazon.

Para citar - ABNT NBR 6023:2018

SANTOS, Antonia Fladiana Nascimento dos; BRITO, Ângela do Céu Ubaiara. Saberes culturais amazônicos e a cultura como práxis: uma análise sob a teoria do uso de Zygmunt Bauman. Cadernos de Pós-graduação, São Paulo, v. 19, n. 2, p. 97-111, jul./dez. 2020. Disponível em: https://doi.org/10.5585/cpg.v19n2.18485. 


\section{Introdução}

O presente estudo consiste no recorte da pesquisa de dissertação de Mestrado intitulada Currículo multiculturalista: os saberes culturais nas práticas pedagógicas dos professores na comunidade do Ipixuna Miranda. Esta teve como finalidade conhecer e descrever o universo cultural da comunidade Ipixuna Miranda, localizada na região amazônica do Amapá, a fim de alicerçar a efetivação de práticas pedagógicas que valorizem os saberes culturais envolvidos no ato educativo, considerando o currículo multiculturalista que envolve os alunos na construção do conhecimento no fator humano.

Para tanto, durante a pesquisa de Mestrado, foi utilizada como fundamentação teórica, a análise cultural baseada na práxis humana de Bauman (2012, 2013). Além disso, foram utilizadas referências acerca da concepção curricular cujo currículo exerce papel central como práxis social e com função socializadora de cultura de Sacristán (2000), assim como referências acerca de prática pedagógica alicerçada no multiculturalismo crítico, teorizadas por Mclaren (1997) e nas experiências da Educação Intercultural defendidas por Candau (2012). Como referência teórico-metodológica, este estudo recorre à Análise de Conteúdo fundamentada em Bardin (2016).

Partindo-se dessa perspectiva e desta base teórico-metodológica, este trabalho tem por objetivo investigar quais as contribuições da teoria do uso, fundamentada em Zygmunt Bauman, para a análise cultural da Amazônia amapaense. As peculiaridades da cultura amazônica configuram-se de forma que as populações tratem as águas como estradas, façam uso de utensílios que lhes são essenciais para a manutenção da vida na floresta, além de lidar de um modo muito familiar com as intempéries, tais como tempestades, chuvas, perda de colheitas, caçadas e incidentes ocorridos nelas.

Desta forma, jovens e crianças aprendem a lidar com tais circunstâncias tanto pela vivência destas, como pelos relatos das experiências/vivências feitos por seus familiares. Portanto, faz-se necessária uma escola, uma concepção de currículo que, para além do atendimento das demandas sociais da atualidade, seja capaz de agregar, às suas práticas, vivências e saberes dos amazônidas.

A respeito do locus em que a pesquisa se encontra e se estrutura, o caminhar entre os tablados e as pontes é necessário para o (re)conhecimento do lugar. Locais de entrada, estas pontes e tablados são sempre os primeiros lugares onde se pisa quando se chega em qualquer comunidade ribeirinha na Amazônia. A entrada da comunidade é circundada por palmeiras de açaí e outras árvores frutíferas. Tais árvores servem de habitação a várias espécies de pássaros, deixando o local com uma trilha sonora lindíssima vinda das copas das altas árvores.

Para fins deste artigo, este ocupa-se em responder o seguinte questionamento: quais as contribuições da teoria do uso para a análise cultural da Amazônia Amapaense? Tem como objetivo geral: analisar as contribuições da teoria do uso para a análise cultural da Amazônia Amapaense. 
Como objetivos específicos: descrever a história do conceito de cultura, identificar as bases epistemológicas da teoria do uso e identificar os saberes culturais amazônicos a partir das categorias da teoria do uso de Zygmunt Bauman.

Assim, constatou-se que a teoria do uso de Zygmun Bauman possui grandes contribuições na análise do universo cultural amazônico tendo em vista a singularidade peculiar do mesmo, bem como vem colaborar na compreensão da riqueza cultural deste universo amazônico em tempos de hibridizações culturais globalizantes na época da modernidade líquida.

\section{Caminhos históricos do termo cultura}

O termo cultura vem passando, ao longo dos anos, por muitas definições, umas tautológicas, outras contraditórias. No entanto, etimologicamente, carrega a ideia de cultivo, de lavoura, de manipulação da natureza. Do latim "colere", vem a ideia de cultivar, do cultivo agrícola, do labor. Já no curso da história humana, o termo passa por uma transição entre o sentido etimológico do termo e a sua utilização (EAGLENTON, 2000).

O termo "colere" em latim, como termo vernáculo, é demasiado amplo e pode significar desde culto até colonialismo, assim como remete a trabalho e labor. Perceptivelmente, o termo traz em si uma vasta ambivalência. Destaca-se, a priori, a dicotomia natureza e cultura, esta, por vezes, entendida como produto daquela ou vice-versa. Apesar do imbróglio "cultura é um conceito que deriva da natureza" (EAGLENTON, 2000, p.11) e designa, entre outras acepções, a ação da humanidade sobre esta. Sendo a cultura conhecida como a ação humana sobre a natureza, tal conceito é, portanto, internamente ambíguo e, para se encontrar um conceito de cultura pertinente a esta discussão, faz-se necessário discorrer sobre esta ambiguidade interna do termo, uma vez que "a natureza produz cultura que altera a natureza" (ibidem, p.13)

Deste modo, a atividade humana sob a natureza está no centro da ambiguidade que gera a ideia de cultura, estando entre os mecanismos da condição humana destinados a serem determinados e aqueles que dependem diretamente de suas escolhas, abrindo assim espaço para a "liberdade" e a "autodeterminação". O conceito delineia-se, portanto, no emprego da liberdade humana e na delimitação de um escopo, cercando as escolhas infinitas em um padrão finito, compreensível e administrável. Tendo a natureza suas próprias regras, a cultura é, por assim dizer, a constante construção e desconstrução das regras que atuam sobre ela, nas ambivalências liberdade e determinismo, descrição e contemplação, singularidade e uniformidade, disciplina e subversão (BAUMAN, 2012).

No período clássico, já se percebia essa diferença quando o ser culto indicava um ideal contemplativo. $\mathrm{Na}$ época medieval, o termo preconizava preparação do homem para a vida eterna (VILLA, 2000). O ser humano, de natureza estável e uniforme, como pregava a visão iluminista, 
era então convocado a cultivar intrínseca relação com a natureza, trabalhando seu eu interior através da estética nas artes e nas ciências. Todavia, não ocorre que os seres inacabados pudessem cultivar a si próprios, sendo necessário algo superior, mas de invenção humana, para o ofício de instruir àqueles que não eram "iluminados" nas artes e nas ciências. Convencionou-se, portanto, empregar a ideia de cultura a um ideal reflexivo e de refinamento humano passível de transmissão através do fruto do movimento iluminista, o Estado-nação.

Com o advento da modernidade, o termo cultura liga-se à palavra civilização. Diante disso, a noção de cultura civilizatória deve ser propagada por povos dos mais iluminados aos menos iluminados "sob o status de ferramenta básica para a construção de uma nação, de um Estado e de um Estado-nação - ao mesmo tempo confiando essa ferramenta às mãos de uma classe instruída" (BAUMAN, 2013 p. 14). Assim, a classe instruída envolta com o manto da cultura e da civilidade, segundo ambivalência a destacar-se, encontra anuência na obediência dos súditos e na solidariedade dos compatriotas a um estímulo para missão de esclarecer o povo, salvando-o de seu estado de barbárie, um estímulo para o colonialismo (BAUMAN, 2013).

Partindo dessa perspectiva, Williams (1976 apud EAGLETON, 2000) sugere que o termo cultura pode trazer diferentes significações a partir da instituição do Estado-nação e do colonialismo. Para o primeiro, cultura é compreendida como civilização, esta é reconhecida como sinônimo de ordenamento de conduta para a fuga da barbárie, remodelando mentes e corpos, tornando-os dóceis de modo a ressignificar costumes e morais, tornando-os agentes que corroboram com a ideia de paz, amigos da ordem política, do progresso intelectual e material e ainda associada a uma dimensão político-imperialista-colonialista. Já para o colonialismo, a cultura é concebida como crítica à política aristocrata pré-industrial da era moderna, colocada distante de um ideal individual e mais próximo de uma dimensão social como crítica e alternativa à vida política-imperialista-colonialista.

Esta segunda noção de cultura, a partir da concepção colonialista, configura-se, portanto, como a visão moderna que foge dos universais culturais iluministas. Estes universais compreende a cultura não como uma "narrativa grandiosa e linear, mas uma diversidade de formas de vida específicas, cada uma das quais com as próprias leis de evolução" (EAGLENTON, 2000 p. 23). Sendo assim, esta concepção corrobora com a noção contrária de civilidade, destacando o momento - meados do século XIX início do XX - em que os dois termos já não andavam mais de mãos dadas.

O período subsequente a este breve histórico, pela modificação do conceito de cultura através da história, é o que alguns autores denominam de "pós-modernidade", "modernidade tardia", "hipermodernidade", "modernidade líquida" ou "segunda modernidade.” Nele, a natureza e 
o universo, palcos da cultura, são compreendidos tão somente como ambiente para as escolhas, atividades, triunfos e erros humanos, assumindo formas cada vez mais instáveis, instabilizantes, multiformes, caprichosas e cheias de surpresas, ou seja, cada vez mais humanas (BAUMAN, 2012).

A cultura deixa de ser a crítica à política para ser a própria política. A cultura na era pósmoderna, de acordo com Eagleton (2000), “define-se em termos do comportamento, e o conteúdo da cultura é feito dessas formas de comportamento" (p. 50). Durante algum tempo, a cultura denotou uma excessiva seletividade, ao passo que atualmente possui uma volubilidade extrema que contempla quase tudo na vida de base empírica da realidade material ou não. Em tempos de modernidade tardia, a "cultura enquanto signo, imagem, significado, valor, identidade, solidariedade e auto expressão é a própria moeda de combate político e não a sua alternativa" (ibidem, p. 57).

Neste sentido, para o alcance dos objetivos propostos neste artigo, destaca-se que a cultura como um processo de subjetivação e afirmação das identidades não se faz pertinente. No entanto, há a ideação de cultura como práxis que - por assim dizer - se utiliza da subjetivação da cultura, não como um fim em si mesmo, mas como ferramenta no auxílio da compreensão do universo semântico de significação dos fenômenos culturais. Isto posto, compreende-se como uma das bases epistemológicas que sustenta a pesquisa aquela que entende "que cada conjunto [de experiências] só continua significativo no campo semântico de um universo discursivo escolhido, e que nenhum universo contém a totalidade da experiência humana" (BAUMAN, 2012 p. 218).

\section{Teoria do uso e suas diferenciações}

Antes de desenvolver o conceito de cultura como práxis, ou teoria do uso, Bauman (2012; 2013) expõe o desenvolvimento do termo cultura na história a partir de três campos semânticos de universos distintos, a saber, o conceito de cultura semântico e hierárquico, o diferencial e o generalista. O conceito de cultura a partir do campo semântico e hierárquico, segundo Bauman (2012), é concebido como uma propriedade do homem e a ele extrínseca "que pode ser adquirida, dissipada, manipulada, transformada, moldada e adaptada" [...], mas também pode ser abandonada, nua e crua, como uma terra inculta, largada e [...] selvagem"(p. 91). Ainda segundo Bauman (2012), todo esse trabalho de modelagem e adaptação deve ser "cultivado" num longo processo de "culturação", através do desenvolvimento das mais diferentes técnicas.

Entretanto, para que esse desenvolvimento ocorra, faz-se necessário o desenvolvimento de capacidades intrínsecas ao ser humano, cultivadas através dos processos educacionais. Deste modo, Bauman (2012) concebe a ideia de transmissão cultural para o desenvolvimento dessas capacidades, de pessoas mais cultas a outras menos cultas, a qual denota alto teor valorativo. Como um ideal a 
ser seguido, nesta perspectiva, cultura é "o esforço consciente, fervoroso e prolongado para atingir esse ideal" (BAUMAN, 2012 p. 93).

Destarte, a acepção de cultura hierárquica, segundo Bauman (2012), faz eclodir no senso comum social duas equivocadas abstrações sobre ela. A primeira denota o outro como alguém que necessita ser retirado de seu estado de ignorância para um estágio de não ignorância, ou seja, o outro é sempre considerado inferior e ignorante. A segunda trata o outro como personagem exótico e folclórico a partir de um entendimento somente artístico/estético do conceito de cultura. Ao se falar de cultura amazônida, a última abstração é bastante comum.

Ao contrário do primeiro, o segundo campo semântico é o que Bauman (2012) chama de conceito diferencial de cultura, considerado algo intrínseco ao ser humano. Desde a antiguidade, o conceito diferencial de cultura se manifestava, não como apresentado na modernidade, mas assemelhando-se com o que os gregos consideram "povos bárbaros" aos que estavam fora de seus domínios. Entretanto, a priori, a busca da epistemologia cultural no campo semântico diferencial não se firmou nem na explicação de características genéticas, nem nas universalidades culturais, mas nas personalidades. Assim, "Culturas são a psicologia individual ampliada na tela, ganhando proporções gigantescas e um longo tempo de duração" (BENEDICT, 1932 p. 24 apud BAUMAN, 2012, p.118).

A posteriori, este mesmo campo semântico de conceituação cultural é alicerçado pela linguística estrutural, adaptando para o estudo "culturológico" as noções de significantes trabalhadas na linguística. Destarte, considerar padrões comportamentais de uma cultura, tal como vista de fora por um espectador que desconheça o aspecto "semântico" do comportamento que se descreve seria, do ponto de vista diferencial, um equívoco. Assim, a junção entre as duas acepções do diferencialismo cultural citadas cria, por assim dizer, uma defesa excessiva da "autoidentidade" e da "singularidade cultural" ao ponto de dividir a humanidade numa multiplicidade de conglomerados humanos autossuficientes, sem a possibilidade de relacionamentos entre si (BAUMAN, 2012 p.119-120).

No que concerne ao terceiro campo semântico do conceito de cultura, há a tentativa de defini-la como conjunto único, total de significados e ferramentas que se atribui apenas à humanidade, por meio da prerrogativa de que somente os seres humanos possuem estrutura social, que minimiza o individual e prioriza o social no estabelecimento de "universais éticos" e na capacidade humana de pensar e produzir símbolos e signos atribuindo-lhes significados coletivamente por intermédio da linguagem. Nesta tentativa, ocorre a busca da uniformidade cultural da raça humana através das descrições generalizantes apoiadas nas características acima descritas. "Nesse sentido amplo, podemos dizer que a cultura [é a] qualidade genérica, como atributo universal da espécie 
humana, na condição que distingue de todas as outras espécies animais, é a capacidade de impor ao mundo novas estruturas" (BAUMAN, 2012 p. 150).

Ademais, há a prerrogativa humana de possuir estrutura social de caráter funcional e de desenvolver artefatos culturais, que são comuns a qualquer cultura, para garantir a sobrevivência do sistema social como um todo. Essa estrutura universal, sob a ótica da cultura na perspectiva genérica, serve para suprir necessidades essenciais do ser humano por meio de "instituições artificiais", como a escola, a família, o Estado-nação, entre outras. Como uma peculiaridade humana, tais instituições possuem também a função, dentro do modelo-estrutural-funcionalista de sistema social, do controle dos indivíduos, sempre sob a ambivalência desejo/satisfação humana. De igual modo, o ser humano ainda é o único que consegue desenvolver uma espécie de fuga ao controle imposto "por meio da fantasia, literatura, teatro, contos populares, jogos, rituais religiosos[...]" (BAUMAN, 2012 p. 137).

De modo análogo ao conceito genérico de cultura, expõe-se, a partir de agora, mais um conceito de cultura trazido por Bauman (2012) que a considera como estrutura ou compreensão estruturalista de cultura. Segundo o autor, cultura pode ser considerada como

[...] o conjunto de regras geradas historicamente selecionadas pela espécie humana, que governam a um só tempo a atividade mental e prática do indivíduo humano. De vez que esse conjunto de regras se condensa nas estruturas sociais, ele parece ao indivíduo uma necessidade transcendental semelhante à lei; graças à sua inexaurível capacidade de organização, é vivenciado pelo mesmo indivíduo como sua liberdade criativa. (BAUMAN, 2012, p. 178).

Pelo exposto, parece praticável ao desenvolvimento desta pesquisa essa noção estrutural de cultura, sobretudo quando há nela o aspecto de constante construção e reconstrução estrutural também tipicamente humanas. Entretanto, há algumas diferenças que precisam ser expostas para que se compreenda a análise cultural de cunho estrutural e a análise que define a cultura como práxis humana defendida neste trabalho.

Em primeiro lugar, a perspectiva estrutural de cultura é emprestada da área da linguística, na qual reside a concepção de canalizar todas as manifestações humanas a partir dos processos linguísticos e do desejo de transmitir informações consideradas úteis ou importantes. Há ainda a asserção da "comunicação pura" que, transferida para a análise cultural, configura-se na noção de "cultura pura". Não obstante, as questões no campo cultural não podem ser tratadas somente, como na linguística, sob a prerrogativa da transmissão de informações úteis. Se assim fosse, não se poderia ocupar das questões não linguísticas, como vestuários, meios de transportes, comidas, padrões de lazer, entre outras; nem mesmo na língua existe a "pureza" das manifestações, então não se pode falar de "cultura pura" (BAUMAN, 2012) 
Assim como nas linguagens, nas culturas ocorre a chamada "lei da parcimônia", em que uma variedade linguística ou artefato pertencente apenas a uma conjuntura tende, com o processo histórico, a desaparecer. Mas tipos semelhantes e alternativos são colocados no lugar com um grau de comutação e redundância entre os sistemas sociais, muito grande (BAUMAN, 2012)

Outro ponto de discordância entre as concepções estrutural e praxiológica de cultura está na natureza comunicativa da linguagem, que nem sempre pode ser atribuída à cultura. Um artista, por exemplo, pode não querer comunicar-se, mas somente expressar-se. Tal natureza comunicativa possui o pressuposto de que todo ato de comunicação é em si estruturado, ordenado, organizado e é sempre dado de quem comunica para seu receptor.

Pelo exposto, a perspectiva estruturalista de cultura tem como proposta um ordenamento, uma estruturação, uma organização, transferida da linguística ao social e ao cultural, sob o entendimento de que é necessário à vida humana um conjunto de preceitos morais com uma integração de regras específicas, ajudando na difícil tarefa de administrar o imprevisível e o natural. À humanidade e a sua evidente organização social desenvolvida ao longo de sua história se faz pertinente prezar a constância e o presumível, bem como desprezar o imprevisível, o incomum, daí a necessidade da ordem e da eficiente função orientadora da cultura.

Nesse por menor, encontra-se um ponto de convergência entre a cultura do ponto de vista estrutural e a perspectiva praxiológica de cultura, entendendo-se a necessidade de manutenção de uma estruturação social e, por sua vez, de manutenção de signos, artefatos e elementos culturais atrelados à resiliência da identidade cultural de um local, para que o mesmo não pereça na absolutização dos hibridismos culturais da modernidade líquida.

Na perspectiva da cultura como práxis, o social não está apartado do cultural, mas é intrínseco a ele e baseado no significado. Assim, Bauman (2012, p. 215) afirma que a "estrutura social existe mediante o processo sempre contínuo da práxis social”, ou seja, a proposta estruturalista só é concebida dentro da cultura praxiológica se, e somente se, estiver entrelaçada com as relações humanas embebidas de significados. É neste sentido, portanto, que se delineiam as prerrogativas epistemológicas de análise da cultura para fins desta investigação que tem como categorias o "significado, valor, propósito, desenvolvimento, ideal” (BAUMAN, 2012 p. 220).

\section{Procedimentos metodológicos}

O presente estudo trata-se de uma pesquisa educacional realizada na comunidade do Ipixuna Miranda, que se apresenta rica no que diz respeito à diversidade cultural da região do Beira Amazonas, no estado do Amapá. Para fins deste trabalho, foi realizado um estado da arte sobre os conceitos de cultura baseado em autores amazônicos, bem como sobre a teoria do uso de Bauman. 
Os caminhos metodológicos fundamentam-se na abordagem qualitativa de pesquisa, pautados na epistemologia do estudo de caso como método de pesquisa, com a entrevista semiestruturada como técnica de coleta de dados.

O estudo de caso é "usado para contribuir em muitas situações buscando [...] entender fenômenos sociais complexos que retenham uma perspectiva holística e do mundo real" (YIN, 2015 p. 4) [grifo nosso]. Para Yin (2015), o estudo em questão é denso e dividido em duas partes. Assim, o estudo de caso consiste em " uma instigação empírica que investiga um fenômeno contemporâneo (o 'caso') em profundidade e em seu contexto de mundo real, especialmente quando os limites entre o fenômeno e o contexto puderem não ser claramente evidentes" (ibidem, p.17).

A pesquisa foi submetida à apreciação do Conselho de Ética da Universidade Federal do Amapá (Unifap) e aprovada sob o n 4.061.663. Antes do início de cada entrevista, neste momento individual e previamente agendado, os participantes foram informados que aquele momento seria uma conversa informal, gravada em áudio e que seu uso seria estritamente para fins de pesquisa, sem nenhuma outra fonte de divulgação. Foram realizadas doze entrevistas com pessoas da comunidade escolhidas pelos critérios de idade e disponibilidade. Para a coleta de dados a partir de diferentes perspectivas narrativas, foi realizada a divisão de 3 grupos diferentes, assim divididos: quatro entrevistas com pessoas entre dezesseis e vinte e sete anos de idade, quatro entre pessoas de quarenta a sessenta anos de idade e quatro com os mais antigos moradores da comunidade acima de sessenta anos.

Os dados foram analisados por meio da análise de conteúdo baseada nos postulados de Bardin (2016) e que se justifica por possuir caráter amplo nas interpretações dos diversos tipos de comunicações. Para a análise dos saberes culturais, buscou-se entender se "o que eu julgo ver na mensagem estará lá efetivamente contido ao ponto de poder esta visão muito pessoal ser partilhada por outros" (BARDIN, 2016 p. 34-35) [grifo nosso].

Outro ponto de destaque no conceito da análise de conteúdo de Bardin (2016) se refere à descrição e à categorização de dados, artifício basilar para o presente texto. Portanto, utilizando as categorias da Teoria do uso de Zygmunt Bauman, realizou-se, a partir destas, uma descrição dos saberes culturais da comunidade do Ipixuna Miranda, assim como a aplicação das categorias de Bauman, desenvolvimento, valor, ideal, significado e propósito, aos saberes identificados nas entrevistas.

\section{Saberes culturais amazônicos e as categorias da teoria do uso de Zygmunt Bauman}

Com as intersecções originadas dos povos participantes do processo de colonização e ocupação do espaço amazônico, os saberes que hoje conhecemos como "da Amazônia” são rodeados 
de uma aura imanente e metafísica que ultrapassa modelos de religiosidades, perpassando pelas manifestações artísticas, refletindo a relação do homem com a natureza, assim, privilegiando o imaginário e o estético.

Desta forma, alguns costumes de povos indígenas, como é o caso do uso da rede, por exemplo, são reverberados até os dias atuais (HERIARTE, 1975, p. 183 apud PORRO, 2017, p. 55). Este ponto específico tomar-se-á como referência para destacar uma das categorias de análise cultural da teoria do uso, a saber, o desenvolvimento. A herança cultural indígena perpassa pela questão do desenvolvimento, se analisarmos como determinados costumes, hábitos e práticas estão no cotidiano cultural atual mesmo que de forma diferente, mas sem objetar sua presença.

De modo análogo, tem-se o ciclo do ouro elástico na Amazônia e sua carga de sofrimento enfrentada pelos aviados ${ }^{1}-$ sejam índios ou nordestinos. Tais sofrimentos vão desde a escravidão a diferentes tipos de tortura, tais como chicotes e mutilações. Este tipo de situação pode ser vista em forma de denúncia nos escritos de Euclides da Cunha, famoso pelo épico "Os sertões". Em ensaio póstumo relativo à Amazônia, intitulado "À margem da história”, onde relata o episódio "Judas Asverus", Cunha associa a prática de fabricar um boneco de palha e lançá-lo em uma embarcação no rio sob pedradas de uma grande multidão uma forma de canalizar as frustrações dos aviados que foram ludibriados pelas promessas de trabalho e riqueza e encontraram somente penúria e cativeiro. Sobre este assunto, Pizarro (2012) comenta que:

\footnotetext{
A comemoração que revela em 'Judas Averus' é uma peça mestra. O Judas feito de palha, ramos e restos de vestimentas é lançado ao rio de pé, numa embarcação. Das margens, a multidão o apedreja, projetando nele sua sorte, até destruí-lo. A leitura de Euclides está de acordos com seus princípios. A sensação de triunfo que ele encontra na multidão tem também outras leituras simbólicas, assim o castigo teria, sem dúvida alguma [...] outros destinatários culpados (PIZARRO, 2012 p.140).
}

Destarte, percebe-se como práticas realizadas no ambiente cultural amazônico advêm de outras práticas, sentidos, sensações e experiências de povos que viveram por aqui desde os mais longínquos tempos deixando suas marcas, seja na cultura material ou simbólica. O episódio narrado acima denota um saber cultural praticado pelos povos da Amazônia até os dias atuais e embebido de significado, outra categoria de análise cultural da chamada teoria do uso.

De modo congênere, o lazer dos escravos no universo cultural, à época da escravidão, tinha o propósito de permitir certa fuga de uma realidade tão perversa e desumana. Com as devidas fusões, atualmente os folguedos e festas de santos espalhadas por toda a Amazônia são herança dessa ludicidade africana nas manifestações de um povo que vive com as agruras de uma terra que, assim como dá vida, a retira nos muitos naufrágios, enchentes, queimadas, caçadas malsucedidas, 
malárias e outras doenças. Assim, identifica-se aqui mais uma categoria da teoria do uso, a saber, a categoria do propósito.

O rio na Amazônia é tudo. É por onde passam as pessoas, é a rua, é o sustento, é a vida. Como um emaranhado materializado pelo grande Amazonas e seus afluentes, as águas são prestímanas da realidade, transfigurando, inebriando, restaurando, sacudindo, ocultando embarcações num encantamento, tal como alimenta inúmeras populações desde as mais longínquas datas. É por meio dele que se desenvolve o cultural, o simbólico, sustentado por botos, uiaras, cobras-nonato, anhangas, boiunas, etc. É no rio que as crianças aprendem desde muito pequenas a "puxar"² um peixe, "anadar", remar o casquinho, "sentar malhadeira", crescendo e observando a natureza, conhecendo o sinal da chuva, da tempestade, dos ventos, das calmarias, dos dias e das noites, aprendendo com as marés e com o regime das águas, o relógio regulador da vida (LOUREIRO, 2015 p. 138-139).

Neste tocante, ressalta-se como o rio e tudo o mais que advêm dele é ponto crucial na vida do amazônida, deste modo, também o é em qualquer análise cultural que se ocupa da Amazônia. Pontua-se aqui, portanto, mais uma das categorias de análise cultural declaradas mais acima no texto, a saber, o valor.

De igual modo, o ambiente cultural amazônico tem como um de seus palcos a floresta. É um espetáculo à parte, sendo também espaço de devaneios dos primeiros viajantes e de grandes aventuras cavalheirescas. É fonte de vida, sustento, potencial econômico, a partir das relações que o homem estabelece com a natureza. No campo do imaginário, a floresta guarda sob suas árvores o Curupira, mãe-do-mato e gênio que guarda a floresta, o Tupana, que com as trovejadas e os raios carboniza florestas e homens, o Poromina-Minare, que passeia entre a floresta e a cidade em uma viagem com muitos acidentes. Há também os animais da inefável floresta metamorfoseando-se e engravidando as mulheres como o vaga-lume e os sapos-cururus. Há ainda Sapo-Taborequê gritando que o que mata as pessoas é o medo, além de crianças, como o filho de Ualipera, que morreu, suando sangue por ter dançado com uma mulher menstruada, transforma-se em uma estrela (LOUREIRO, 2015).

Assim, o relato que segue expressa a contação de uma lenda muito comum nas terras amazônicas, possuidora de várias versões. O relatado abaixo corresponde à versão da comunidade locus desta pesquisa. Não somente esta história, mas várias outras escutas das memórias e oralidades dos comunitários contam seus traços de valores, crenças, costumes, lazer e tradições. Pretende-se com tal relato destacar a categoria do significado, uma vez que essa versão traz peculiaridades da comunidade do Ipixuna Miranda: 
Aí deram dinheiro pra ele, mas era dinheiro mesmo no sonho dele né, aí ensinaram tudo pra ele, como era que e o que era pra ele ir lá, ir roçar lá, um aterro grande, e lá mesmo era um, negócio de uma terra alta né!? Que pra ele ir lá, ir cavar lá que tinha um dinheiro pra ele, mas não era pra ele contar nada pra ninguém. Então lá dentro, pra ele se ajudar, era pra ele. Vinha surgir uns largatos, quando ele começasse a cavar e vinha surgir uns largato, né, quando ele visse o lagarto, não era pra ele fazer nada, que ele ia ficar lá espiando ele, cavando o buraco. Tá. Ele pegou, de manhã, ele contou pro cunhado dele, aí era só pra ele o dinheiro, contou pro cunhado dele, aí chegou lá, foram cavar lá. "Não, mas hoje nós tira esse dinheiro daqui". Cavaram, cavaram, chegaram no avidar ${ }^{5}$. [...] “Opa, agora nós achemo o dinheiro, agora nós já vai embora aqui dessa terra. Tá; cavaram, quando chegaram no lá no avidar, puxaram o avidar, tinha nadinha lá dentro, só tava uma medalha velha, que não prestava pra nada e uma chave, porque, por quê ele contou e era pra ele o dinheiro né!? Foi contar pro cunhado. E diz que essa visage ${ }^{6}$ era que fazia lá na beira, aí caiu pra água tudo, ai acabou a visage. Mas disque era isso que fazia, e que tinha dinheiro mesmo lá (RELATO DE ENTREVISTA DA PESQUISA, 2019).

Da floresta advêm, também, saberes milenares repassados de geração em geração que, durante muito tempo, salvaram vidas a partir de conhecimentos das plantas e ervas medicinais. Tais saberes originam-se na tradição indígena que associa todos os aspectos da vida à sua ancestralidade transcendente com uma tradição repleta de cerimonias e rituais nas quais a cura de enfermidades e manipulação dos remédios da floresta caminhavam pari passu. Assim, destaca-se, mais uma vez, a categoria do valor a partir do relato de entrevista da pesquisa abaixo mencionado:

Um dia eu tava tirando açaí, com esse meu neto. Aí ele tirou, essa saquinha vermelhinha cheia. Aí ele desceu de lá: "Mãe um bicho me ferrou". Aí ele desceu com dois cachos. Aí eu tava debulhando ${ }^{7}$ lá. "Mamãe, a minha garganta já tá tapando, eu não tô conseguindo nem puxar o forgo ${ }^{8 "}$. E agora o que que eu fazia, não tinha nem água pra dá pra ele, eu só olhei tinha um pracaxizeiro ${ }^{9}$ assim, perto, fui lá tirei aquelas cascas de pracaxi, raspei rapidinho aquele sumo daquela casca: "toma, bota na tua boca, e vai coisando, e vai engolindo" pois ele foi... foi... foi... Com 15 minutos, ele melhorou, atacou mais a garganta, porque ataca logo a garganta. (RELATO DE ENTREVISTA DA PESQUISA, 2019)

A práxis cultural possui estruturas basilares provenientes de um habitus alicerçado nas vivências em esferas formadoras, como a família e a escola. É neste pormenor, então, que se entende como o tratamento com a aprendizagem dos alunos e os conteúdos culturalmente selecionados é fator diferencial no desenvolvimento desta práxis. De modo similar, a relação do currículo com as culturas dos aprendizes é de essencial importância para o desenvolvimento e consolidação de uma consciência praxiológica nos mesmos, assim como capacidade de resiliência e instrumento de busca à emancipação de sua realidade social.

Todavia, a contemplação das culturas dos aprendizes nos projetos de currículo não é uma realidade concreta. Uma das finalidades dos projetos curriculares é preparar indivíduos para serem cidadãos ativos, críticos, solidários e democraticamente formados para atuação em uma sociedade igualmente democrática e solidária. As escolas que trabalham com tal direcionamento precisam 
encontrar estratégias para que alunos possam "tomar decisões, solicitar a colaboração de seus companheiros/as, a debater e criticar sem medo de ser sancionado negativamente por opinar e defender posturas contrárias as do/a docente de plantão” (SANTOMÉ, 2013 p. 155).

Destarte, o relato que segue retrata a figura de um jovem comunitário da Região do Beira Amazonas que fora estudante em uma das escolas da região, mais especificamente da Escola Família Agrícola-EFA do Macacoari, onde terminara seus estudos saindo de lá com o diploma de técnico agrícola. Saíra da comunidade para estudar ciências biológicas e retornara, já concursado, como técnico agrícola para trabalhar na região. Apesar de não ser oficialmente um líder comunitário, sua fala eloquente e seu trabalho na persuasão de seus pares à adesão ao projeto de uma Associação para lhes representar no mercado mundo afora, colocam-no na posição de liderança social que teve sua formação base na própria comunidade. Tem-se, portanto, a compleição de uma das categorias de análise do presente trabalho, associada à formação de um indivíduo em sua realidade social, a saber, a categoria do ideal.

\begin{abstract}
O jovem rapaz, filho da comunidade, com seus menos de trinta anos tem conversa fluida, alongada e prolixa. Naquela manhã o diálogo versava sobre o movimento de criação da Associação dos extrativistas de açaí da Região do Beira Amazonas. Pela ocasião, o rapaz com seu palavreado técnico, uma vez que trabalha como técnico agrícola na comunidade, e loquaz comentava dos trâmites burocráticos para a criação da associação que ajudaria, entre outras coisas, na valorização econômica e social do produto do trabalho dos comunitários, com o alcance de selos internacionais que beneficiariam a venda e agregaria valor qualitativo ao açaí da região. Para além disso, o rapaz falava da dificuldade de engajamento dos extrativistas ao projeto da associação, tendo em vista o processo burocrático e as longas e sucessivas reuniões deliberativas para enfim se chegar a um consenso, ou seja, uma demanda de participação social (RELATO DE PESQUISA, 2019).
\end{abstract}

Muito embora tenha a cultura amazônica sua origem miscigenada, há nela uma tradição que se configura em práticas, hábitos, procedimentos e usos que lhe dão identidade. Ao entrar em contato com a comunidade locus da pesquisa, pôde-se perceber alguns de seus signos, códigos e saberes perdidos com o tempo. Como exemplo do desaparecimento desses códigos, signos e saberes, está a inexistência da figura da parteira na comunidade. Dona de um saber que é passado hereditariamente, a parteira, em uma comunidade ribeirinha, é dotada de uma aura transcendente que vai além de ajudar uma criança vir ao mundo, mas alcança, sobretudo, a saúde e o bem-estar da mãe e do recém-nascido muitos dias ainda após o nascimento da criança.

Entretanto, reconhece-se a mudança de usos e práticas ligadas aos signos e aos códigos no interior das culturas de modo geral, fato que se pode destacar na categoria da teoria do uso, a saber, o desenvolvimento. Porém é pertinente descartar o caráter abjurador de tais perdas, tornando-as ainda mais sérias, uma vez que o não conhecimento destas pelas novas gerações pode 
acarretar no fenecer de tais elementos culturais. O relato que segue demonstra certo pesar na fala de um dos entrevistados:

\footnotetext{
O café e a soleira da porta são convidativos a uma bela e alongada prosa na comunidade à beira do rio onde o dia só se vai quando o relógio marca noite. O palavreado versava sobre o que é ser um ribeirinho. O homem, de prosa alegre, comentava: "olha eu acho que o que é ser ribeirinho é, foi aquilo que o 'antes' queridos nosso deixaram pra gente entendeu, que nós não evoluímo, não deu, porque nós construimo, nós não, nós não tamo construindo aquilo que eles deixaram pra nós, nós deixamo acabar entendeu, eu acho que ser ribeirinho (RELATO DE PESQUISA, 2019).
}

Isto posto, para tratar a ostentosa riqueza cultural amazônica, faz-se necessária uma perspectiva de análise cultural que consiga agregar a multiplicidade de fenômenos culturais de forma sistemática, sem abandonar a rigorosidade científica, no sentido de colaborar na capacidade de uma estrutura social e manter seus elementos culturais básicos apesar dos processos de hibridização culturais em uma era globalizada dos tempos da modernidade líquida.

Portanto, percebe-se o quanto a teoria do uso possui valiosas contribuições para tal análise da cultura amazônica no sentido de corroborar com o sentimento de pertença relacionado com a identidade dos cidadãos ante sua própria cultura, que culmina na noção de permanência e defesa no/do lugar.

\section{Considerações finais}

$\mathrm{Na}$ Amazônia há uma fortíssima incidência de miscigenação cultural - a indígena, a afro e a europeia -, discursos e vozes incomparáveis em qualquer continente, bem como infinitos modos de relações humanas e com a natureza. Entretanto, ocorre um déficit nas escutas, compreensão de marcos culturais e históricos, o que impossibilita o entendimento de tais relações nas suas mais complexas facetas. Desta forma, entende-se que o trabalho com a cultura amazônica deve-se pautar, precipuamente, na observância das matrizes culturais aludidas tendo em vista a composição basilar da mesma, sob pena de não se conseguir abranger a riqueza de tal cultura e, portanto, de um desenvolvimento analítico cultural alicerçado na reprodução mecânica e desatrelada da realidade regional.

Os saberes culturais amazônicos encontram-se embalados por uma atmosfera, uma aura real-irreal, pelas condições geográficas de difícil acesso, pelas ligações com a Europa com a qual foi se tecendo numa espécie de segredo com certo invólucro imaginativo, pelos rios e florestas que se constituem na origem e finalidade das comunidades existentes através do entrelaçamento destes elementos com as relações de vida e trabalho. 
Tal atmosfera ainda engrandece a leveza da imaterialidade e do etéreo, valorizando as coisas simples e cotidianas, além de propiciar condições para uma percepção contemplativa desse cotidiano a partir da relação com o próprio tempo que aparenta ser regido não pelo relógio, mas pelos ventos que balançam as copas das árvores e pela correria das águas. Isto posto, compreende-se que a análise cultural baseada na cultura como práxis, ou seja, na teoria do uso, possui grande sincronia com a natureza dos saberes culturais amazônicos e, portanto, inúmeras contribuições para a análise da mesma e assim como colabora na compreensão da riqueza cultural deste universo amazônico em tempos de hibridizações culturais globalizantes na época da modernidade líquida.

\footnotetext{
Notas

1 Termo utilizado para fazer referência a "Negociadores da Amazônia"

2 Expressão muito utilizada na Amazônia que significa pescar peixe com anzol.

3 Termo usado pelos povos ribeirinhos que tem o mesmo sentido de nadar.

${ }^{4}$ Malhadeira é uma espécie de rede colocada no rio para prender os peixes. Depois de "sentada" a rede é retirada com muitas espécies de peixes e até outros animais marinhos.

5 A expressão indica a palavra alguidar, que é um pote de barro muito utilizado para fazer o vinho do açaí, amassandose o fruto com as mãos dentro do alguidar.

${ }^{6} \mathrm{Na}$ linguagem popular da Amazônia significa fantasma, assombração.

${ }^{7}$ Expressão utilizada para designar o ato da retirada do açaí de uma espécie de vassoura a qual fica preso na palmeira.

${ }^{8}$ Expressão que indica fôlego.

9 Um tipo de palmeira comum na Amazônia.
}

\section{Referências}

BARDIN, Laurence. Análise de conteúdo. São Paulo: Edições 70, 2016.

BAUMAN, Zygmunt. A cultura no mundo líquido moderno. Rio de Janeiro: Zahar, 2017.

BAUMAN, Zygmunt. Ensaios sobre o conceito de cultura. Rio de Janeiro: Zahar, 2012.

EAGLETON, Terry. A ideia de Cultura. São Paulo: Editora Unesp, 2005.

LOUREIRO, João de Deus Paes. Cultura Amazônica: uma poética do imaginário - 5 ed. - Manaus: Editora Valer, 2015.

MEIHY, José Carlos Sebe Bom. Manual de história oral - 4 ed. - São Paulo: Edições Loyola, 2000.

PIZARRO, Ana. Amaz̧ônia: as vožes do rio: imaginário e modernização. Belo Horizonte: Editora UFMG, 2012.

PORRO, Antonio. O povo das águas: ensaios de etno-história amazônica. 2 ed. Manaus: EDUA, 2017.

SANTOMÉ, Jurjo Torres. As culturas negadas e silenciadas no currículo. In: SILVA, Tomaz Tadeu da.(org.) Alienígenas na Sala de aula. Petrópolis: Vozes, 2013.

YIN, Robert K. Estudo de caso: planejamento e métodos. - 3 ed. - Porto Alegre: Bookman, 2015. 